\title{
Covid-19 pandemic ARDS lockdown will end within $<2$ months: Depends on cooperation of scholars of doctors and researchers
}

\author{
Ahmed N. Ghanem \\ MD (Urology), FRCS Ed, Mansoura University, Faculty of Medicine, Egypt. \\ Correspondence Author: Ahmed N. Ghanem, MD (Urology), FRCS Ed, Mansoura University, Faculty of Medicine, Egypt. \\ Received date: February 19, 2021; Accepted date: March 06, 2021; Published date: March 18, 2021 \\ Citation: Ahmed N. Ghanem. (2021) Covid-19 pandemic ARDS lockdown will end within <2 months: Depends on cooperation of \\ scholars of doctors and researchers. Clinical Medical Reviews and Reports 3(3); DOI:10.31579/2690-8794/069
}

Copyright: (@) 2021 Ahmed N. Ghanem, This is an open access article distributed under the Creative Commons Attribution License, which permits unrestricted use, distribution, and reproduction in any medium, provided the original work is properly cited.

\begin{abstract}
Coronavirus is here to stay

In January, Nature asked more than 100 immunologists, infectious-disease researchers and virologists working on SARS-CoV-2 whether it could be eradicated. Almost $90 \%$ of respondents think that the coronavirus will become endemic - meaning that it will continue to circulate in pockets of the global population for years to come. But failure to eradicate the virus does not mean that death, illness and social isolation will continue on the scales seen so far. The future will depend heavily on the type of immunity people acquire and how the virus evolves.
\end{abstract}

A different opinion: A minority report of one:

Coronavirus may not go completely away but will be reduced in size and severity and its mortality greatly reduced: An optimistic hopeful minority report, Covid-19 pandemic war lockdown will end triumphantly before the start of May.

Key words: shock; cardiopulmonary arrest; ARDS; covid-19; coma; AKI; multiple organ dysfunction syndrome (MODS), fluid therapy complications

\section{Introduction}

The opinion of Nature is based on a survey that is concluded in this pessimistic depressive title of "Corona virus is here to stay". I wish to express and report my opinion that Corona virous will go away and life returns to normal when Covid-19 will remain dormant and harmless like all serious viral infections of the past that have been prevented by active immunization by vaccination. Furthermore, I wish to express my opinion that the lockdown state of the UK and many countries will end before the start of May. The solid scientific evidence to support this minority report of one is given here. The only problem with validating this theory is that it depends on the collaboration of other scholars of researchers, scientists and doctors and their willingness to collaborate in an immediate study to validate the theory that will be proposed below. I am optimistic that at least two researchers will oblige and perform the validating study as much as I hope will attempt to save the currently acutely ill patients with a concentrated salt solution.

Here I shall report the scientific basis for this hopeful, optimistic minority report that Coronal virous will go away before the start of May. The reason for giving that date is the need for a study to validate the theory that requires a minimum of one month to conclusion and reporting. I also have a vested interest on deciding the start of May to end triumphantly the war of Covid-19 pandemic on humanity before that day. I want to celebrate my $71^{\text {st }}$-birthday with my family outside our house in the UK when this lockdown must end before that. This will be my first time ever to celebrate a birthday of mine. I hope the whole world will join the celebration and rejoice.

Editorial/Brief Communication/Mini review/ Opinion/ LTE or it may be considered as original research article (It is left to the Editor's discretion and choice of one article type then delete others on acceptance, please)

There is currently substantial evidence that reports the research of my ongoing 40-years investigation to precise the patho-aetiology and therapy of the acute respiratory distress syndrome (ARDS). Five books document my 14 new scientific discoveries reported in $>100$ articles and 8 books of which 5 have been published recently [2-6]. I have demonstrated that ARDS [5] is caused by volumetric overload shocks (VOS) [2] induced by excessive fluid gain that complicates fluid therapy of shocks in hospitals $[3,5]$ because of an error that is not the treating physician's fault. The question whether this well-established ARDS is related to that caused by Covid-19 that also kills its victims by causing ARDS was raised [7, 8].

It is well documented now that the wrong Staling's law dictates the faulty rules on fluid therapy that mislead physicians into giving too much fluid therapy during the resuscitation of shock of trauma, haemorrhage and sepsis, acutely ill patients, and prolonged major surgery. This professional research has established that VOS is induced by excessive infusion of fluids during the management of shock [2,4,6] and cause ARDS [5] from which sepsis has proved to be as innocent as the Wolf in Josef' story.

It has been just realized that there is a link between this common type of ARDS, seen in the usual clinical practice but usually attributed to sepsis 
and septic shock, with ARDS of Covid-19. The reader is most likely to have heard this theory for the first time here in this Journal [6] because all my $>100$ articles on the subject reported over the last 4 years do not turn up on searching PubMed! This is because PubMed does not list articles reported in Open Access Journals (OAJ). All my articles, however, do appear on Google Scholars' search with citations and probably in other search engines. There is probably a stupid money cause for PubMed not referencing OAJ which qualifies them for stupidity [7]. Let us hope it is temporary curable stupidity by repenting and rectifying the error by listing OAJ that survived $>2$ years and referencing my articles reported over the last 4 years, not the permanent utter stupidity that is a problem without solution and malady without a cure [7].

I have also been obstructed by top journals of the World by putting a great high and thick fire wall that prevent my articles from penetrating it to inform their readers. These journals have rejected my articles without sending to peer reviewers. This is a deliberate obstruction that is shared by all the top journals in the World and has resulted in delayed recognition of my new 14 discoveries in physics, physiology, and medicine [3] that has clear benefit to science, medicine, and humanity. The editor responsible for each and all these journals must be investigated for inability to recognize genuine new discoveries and scientific advances of articles he received and evaluated.

The Editor-in-Chief of such journals must have the primary responsibility and both him and the publisher should accept resignation or sacking of the responsible sub-editor as he is unfit for the job he is doing. The Editors-in-Chief of these top-rated journals of the World must be held responsible and accountable for rejecting these landmark impactful articles of mine that represent 14 new scientific discoveries in physics, physiology, and medicine [2-6]. They have the right to defend themselves using whatever excuses and proofs on their stand they might have.

The war on Covid-19 pandemic of ARDS has been going on for over a year now. It kills hundreds of thousands of patients every day all over the word and has caused great loss in humans' lives and billions of dollars. I have reasons to believe that this war shall and must end triumphantly soon $[8,9]$. To be precise I predict this lockdown will end before the start of May. This end shall be due to a combination of the eradication of the vicious Covid-19 virus by active immunization that will take longer time to work. Patients of today and tomorrow who are currently critically ill patients dying with ARDS caused by Covid-19 seen every day now deserve an immediate specific therapy that may help saving their lives. This therapy is available now [5].

The therapy has not been tested in Covid-19 induced ARDS yet. I suggested an immediate prospective comparative cohort study of 100 patients to start now. The study should compare the conservative currently practiced therapy for Covid-19 ARDS of one group of 50 patients to another similar randomised group who should get the added hypertonic sodium therapy (HST) to the standard treatment. This should be akin to or better than our prospective cohort study reported in 1990 [9]. The results should compare the two groups with regards to the morbidity and mortality of ARDS on its onset and on the patient's discharge or death.

Such study can be done at any hospital or research centre that receive Covid-19 cases, specifically intensive care units run by consultants of anaesthesia and intensive care. It does not require extra money or much time and should be written up, concluded, and reported within a month. If drug companies have been allowed to reduce the research time of producing a vaccine from 4-5 years to less than one year, the Ethical Committees would kindly allow physicians researchers to reduce prospective studies from a high number of thousands to 100 patients or less particularly as it maintains the statistical power of the study resultsas statisticians should testify. You only need to investigate 100 patients, 50 for each group, and you may not even need to complete the study! I anticipate a clear superiority of HST that will ethically compel the treating physician to switch all patients to HST group that saves their lives.

Treatment using concentrated salt solution of $5 \% \mathrm{NaCl}$ and/or $8.4 \% \mathrm{NaCo}_{3}$ is professionally researched and established by me to save the lives of ARDS patients induced by sodium-free fluid overload that cause the transurethral resection of the prostate (TURP) syndrome known in urology to present with acute dilutional hyponatraemia (DH). This causes VOS which is a shock that complicates other types of shocks hence commonly mistaken for one of the recognized shocks being treated and gets wrongly treated by further volume expansion using crystalloids, colloids and/or blood fluids. This complicates VOS1 into VOS 2 and both causes ARDS. VOS occur seamlessly and unnoticed particularly VOS type 2 of sodium-based fluid that has little or no serological markers.

Thus, VOS 2 is an almost impossible to recognize that complicates fluid therapy of other known type of shocks, cause ARDS, and occur seamlessly and unnoticed without a clear serological marker such as hyponatraemia of VOS 1 . Validation of the volume of retained fluids in a patient can be done in two ways: The volumetric method in litres and the gravimetric method in $\mathrm{Kg}$, and both should be recorded every day during hospital stay, done and compared at hospital admission and at the onset of ARDS as well as the time of hospital discharge or death. The maximum volume of HST used in a single patient is one litre- if it does not work consider the treatment as failure. This may occur in patients with permanent AKI who should go on haemodialysis setting the machine to negative fluid balance to get rid of the retained volume of fluid in the patient's body- they may recover their renal function.

Availability and choice of HST for the trial is summarized here. The concentrated salt solutions of $5 \% \mathrm{NaCl}$ and/or $8.4 \% \mathrm{NaCo} 3$ are available in every hospital now or should be made adequately available before the start of the suggested trial. Sodium bicarbonate is already available in every resuscitation trolley in $200 \mathrm{ml}$ bags of $8.4 \% \mathrm{NaCo}_{3}$ that is known to be used during the resuscitation of shock. The $5 \% \mathrm{NaCl}$ can be made available by any hospital pharmacist in bags of $500 \mathrm{ml}$ or $1000 \mathrm{ml}$ on the doctors' request or readily provided by intravenous fluid manufacturers.

Why use these two fluids concentrations in particular? Because they have been tested and validated previously by me to be absolutely $100 \%$ safe without any complications. The HST of $5 \% \mathrm{NaCl}$ and/or $\% \mathrm{NaCo} 3$ does not cause thrombophlebitis like fluids of higher concentrations. Fluid of lower concentrations are less effective, and its use are a hit or miss experience. A combination of both fluids should be used in every patient treated with it to induce the maximum desired effect of inducing massive diuresis of 4-5 litres of urine by the end of the 1-hour treatment. It is observed that the immediate diuresis that should start during the 1-hour therapy of ARDS producing this massive diuresis SHOULD NOT BE REPLACED by further intravenous fluid therapy as it defeats the objective of therapy.

The diuresed volume of urine must get out of the patient's body and not to be replaced for the immediate recovery of the patient from his coma, ARDS, acute kidney injury (AKI), and cardiovascular and haematological manifestations as well as other hepatic and gastro-intestinal manifestations of the multiple organ dysfunction syndrome (MODS) usually seen in such cases though one system may predominate (Table 1). If the patient is on dialysis, the machine should be set to negative fluid balance. This HST is a magical lifesaving therapy of ARDS or MODS induced by any cause or predisposed by any condition to remove any excess fluid volume retained in the patient's body. It is $100 \%$ safe and most effective in saving the lives of the patients that brings patients back from the dead. Please, stay by the patient's bed side and watch him recover from coma and asks for a drink. It is the best hour you spend in your career life. It is quite simply magical. 


\begin{tabular}{|c|c|c|c|c|}
\hline Cerebral & Cardiovascular & Respiratory & Renal & Hepatic \& GIT \\
\hline $\begin{array}{l}\text { Numbness } \\
\text { Tingling } \\
\text { SBB }^{1} \\
\text { COC }^{2} \\
\text { Convulsions } \\
\text { Coma } \\
\text { PMBCI }^{3}\end{array}$ & $\begin{array}{l}\text { Hypotension } \\
\text { Bradycardia } \\
\text { Dysrhythmia } \\
\text { CV Shock* } \\
\text { Cardiac Arrest } \\
\text { Sudden Death }\end{array}$ & $\begin{array}{l}\text { Cyanosis. } \\
\text { FAM }^{4} \\
\text { APO) } \\
\text { RA }^{6} \\
\text { Arrest } \\
\text { CPA }^{7} \\
\text { Shock lung } \\
\text { ARDS }^{\$}\end{array}$ & $\begin{array}{l}\text { Oliguria } \\
\text { Annuria }^{8} \\
\text { Renal failure or } \\
\text { AKI }^{9} \\
\text { Urea } \uparrow \\
\text { Creatinine } \uparrow\end{array}$ & $\begin{array}{l}\text { Dysfunction: } \\
\text { Bilirubin } \uparrow \\
\text { SGOT } \uparrow \\
\text { Alkaline } \\
\text { Phosphatase } \uparrow . \\
\text { GIT symptoms } \\
\text { DGR }^{10} \\
\text { Paralytic ileus } \\
\text { Nausea \& } \\
\text { Vomiting. }\end{array}$ \\
\hline
\end{tabular}

\section{Table Abbreviations}

$\begin{array}{ll}\mathrm{SBB}^{1} & \text { Sudden bilateral blindness } \\ \mathrm{COC}^{2} & \text { Clouding of consciousness }\end{array}$

$\mathrm{PMBCI}^{3}$ Paralysis mimicking bizarre cerebral infarctions, but is recoverable on instant use of $\mathrm{HST}$ of $5 \% \mathrm{NaCl}$ and/or $\mathrm{NaCo} 3$, and so is coma and $\mathrm{AKI}$

$\mathrm{FAM}^{4} \quad$ Frothing around the mouth

$\mathrm{APO}^{5}$ Acute pulmonary oedema

RA $^{6} \quad$ Respiratory arrest

$\mathrm{CPA}^{7}$ Cardiopulmonary arrest

ARDS \$ Manifests later, on ICU

$\mathrm{AKI}^{9} \quad$ Acute kidney injury

DGR $^{10}$ Delayed gut recovery

CV Shock* Cardiovascular shock of VOS reported here as VOS 1 and VOS2.

Annuria $^{8}$ That is unresponsive to diuretics but responds to HST of $5 \% \mathrm{Ncl}$ and/or $8.4 \% \mathrm{NaCo} 3$

$\mathrm{AKI}^{8} \quad$ Acute kidney injury

Also occurs the excessive bleeding at the surgical site and Leukocytosis occurred in the absence of sepsis and septic shock.

Table 1. The manifestations of VOS 1 of the TURP syndrome for comparison with ARDS manifestations induced by VOS2.

(P.S. Please be prepared by inserting a urinary catheter, if one is not already there, and get two buckets placed next to the patient's bed. When the patient recovers and asks for a drink, both you and your patient may celebrate your success with a drink each on me- just let me know)

I have NOT invented HST myself. The HST was first introduced in 1946 by Danowski TS, Winkler AW, Elkington JR [11] for treating dilutional hyponatraemic (DH) shock induced experimentally in dogs by large intravenous administration of sodium-free fluids that caused $\mathrm{DH}$ that characterizes volumetric overload shock type one (VOS 1) which cause the first type of ARDS. Harrison, R.H., Boren, J.S. and Robinson, J.R. in 1956 [12] were the first to use HST in treating DH of the TURP syndrome in urological practice and clinical practice.
Decades after that HST was considered contraindicated by the authority even in the therapy of DH until 1987 when Ghanem AN, Wojtulewski JA and Penny MD [13] rejuvenated it and reported its successful lifesaving use in the therapy of DH and the TURP syndrome as anecdotal evidence at $\mathrm{Br}$ Med Jour. Ghanem AN and Ward JP reported the first term using VOS in an MD thesis in 1988 and an article in 1990 [10]. In the later prospective cohort study of 100 patients of whom $10 \%$ developed the TURP syndrome, it was established that volumetric overload (VO) is the most highly significant cause for the TURP syndrome $(\mathrm{p}=0007)$ (Table 2 and Figure 1). Also (Table 3 and Figure 2) were taken from another study of 23 patients case series who suffered the TURP syndrome demonstrating VO of 7 litres cause death by ARDS (Figure 2)., while patients who were saved from certain death by HST validated its effective use of lifesaving value (Table 3).

\begin{tabular}{|c|c|c|c|c|c|}
\hline P & T Value & Std. Value & Std. Err & Value & Parameter \\
\hline & & 0.773 & & & Intercept \\
\hline 0.0007 & 3.721 & 1.044 & 0.228 & 0.847 & Fluid Gain (1) \\
\hline 0.0212 & 2.42 & -0.375 & 00.014 & 0.033 & Osmolality \\
\hline 0.0597 & 1.95 & 0.616 & 0.049 & 0.095 & Na+(C_B) \\
\hline 0.4809 & 0.713 & 0.239 & 0.087 & 0.062 & Alb (C_B) \\
\hline 0.2587 & 1.149 & -0.368 & 0.246 & -0.282 & Hb (C_B) \\
\hline 0.4112 & 0.832 & -0.242 & $5.975 E-5$ & $-4.973 E-5$ & Glycine (C_B) \\
\hline
\end{tabular}

Table 2. The multiple regression analysis of total per-operative fluid gain, drop in measured serum osmolality (OsmM), sodium, albumin, Hb and increase in serum glycine occurring immediately post-operatively in relation to signs of the TURP syndrome. Volumetric gain and hypoosmolality are the only significant factors. 


\begin{tabular}{|c|c|c|c|c|c|c|c|c|}
\hline & A & B & C & D & E & $\mathbf{F}$ & G & H \\
\hline 1 & & Gr 1 & Gr 2 & Gr 3 & Gr 3.1 & $\mathrm{Gr} 3.2$ & Hormal & Units \\
\hline 2 & Number of patients & 3 & 10 & 10 & 5 & 5 & Mean & \\
\hline 3 & Age & 71 & 70 & 75 & 72 & 78 & 72 & Year \\
\hline 4 & Body veight (BW) & 69 & 70 & 68 & 71 & 65 & 69 & $\mathrm{~kg}$ \\
\hline 5 & \multicolumn{6}{|c|}{ Postoperative serum solute concentrations:- } & \multicolumn{2}{|c|}{ Preoperative } \\
\hline 6 & Os molality & 271 & 234 & 276 & 282 & 271 & 292 & $\mathrm{mosm} / 1$ \\
\hline 7 & $\mathrm{Na}+$ & 110 & 108 & 120 & 119 & 121 & 139 & $\mathrm{mmol} / 1$ \\
\hline 8 & $\mathrm{Ca}++$ & 1.69 & 1.79 & 1.85 & 1.84 & 1.86 & 2.22 & \\
\hline 9 & $K+(P<.05)$ & 5.6 & 4.8 & 5.0 & 4.9 & 5.0 & 4.46 & i \\
\hline 10 & $\operatorname{Co2}(P=.002)$ & 23.0 & 23.0 & 25.5 & 24.0 & $26-4$ & 27.30 & $"$ \\
\hline 11 & G1 ucose & 13.2 & 17.3 & 16.4 & 15.9 & 16.9 & 6.20 & 7 \\
\hline 12 & Ures $(P=.0726)$ & 26.5 & 9.0 & 6.6 & 6.8 & 6.4 & 6.7 & "i" \\
\hline 13 & Bilirubin ( $<<.05)$ & 19 & 16 & 8 & 6 & 9 & 7 & "i" \\
\hline 14 & AST & 124 & 32 & 20 & 18 & 21 & 20 & 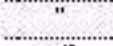 \\
\hline 15 & Protein & 43 & 52 & 48 & 44 & 52 & 62 & $g / 1$ \\
\hline 16 & Al bumin & 23 & 30 & 30 & 28 & 32 & 39 & $"$ \\
\hline 17 & $\mathrm{Hb}(\mathrm{P}=.0018)$ & 119.3 & 127.9 & 114.5 & 105.2 & 123.8 & 138.8 & $"$ \\
\hline 18 & WCC $(P<.005)$ & 18.9 & 16.2 & 7.5 & 7.8 & 7.2 & 8.0 & per HPF \\
\hline 19 & Glucine & & & 10499 & & & 293 & $\mu \mathrm{mol} / 1$ \\
\hline 20 & Therapy & CT & HST & Random: & HST & CT@ & & \\
\hline 21 & Outcome & Death & full Rec. & & ull Rec & Morb.@ & & \\
\hline
\end{tabular}

Table 3. The data of the 23-patients of the case series study [11]; the second clinical study on which this article is based. The significant changes of serum solute contents are shown in bald font with the corresponding p- value. Most of the patients showed manifestation of ARDS (Table 1) of which the cerebral manifestation predominated, being on initial presentation (Regional Anesthesia) and representation of VOS 1 (General Anesthesia). However, most patients were given large volume of saline that elevated serum sodium to near normal while clinical picture became worse. They suffered VOS2 that caused ARDS. The VO of patients to whom these data belongs are shown. Please note the elevation of urea and unurea of Group 1 who died indicated AKI. Elevations oh Bilirubin and AST indicated hepatic dysfunctions. White cell count (WCC) elevation indicated inflammatory response of VOS 2 in ARDS or SIRS in the absence of sepsis.

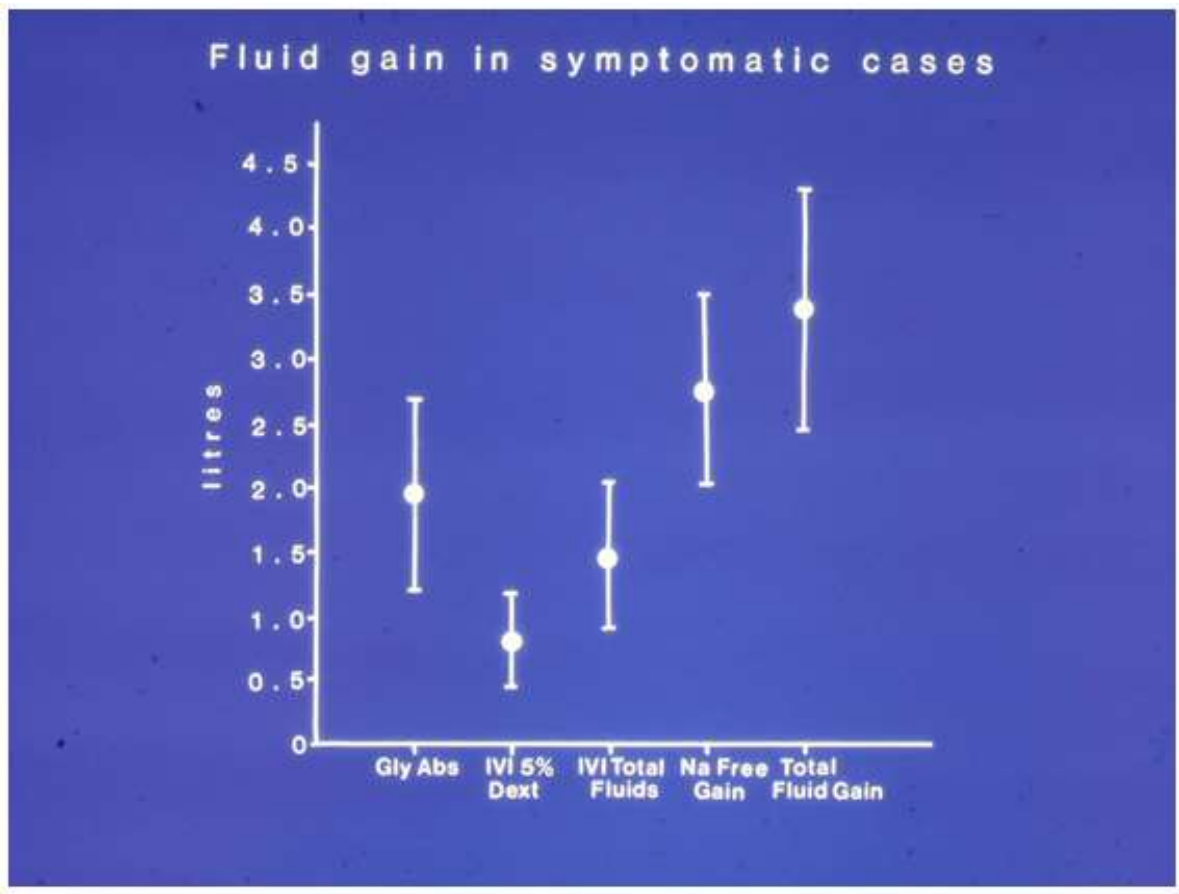

Figure 1. The means and standard deviations of volumetric overload in 10 symptomatic patients presenting with shock and Hyponatremia among 100 consecutive patients during a prospective study on transurethral resection of the prostate. The fluids were of Glycine absorbed (Gly abs), intravenously infused 5\% Dextrose (IVI) Dext) Total IVI fluids, Total Sodium-free fluid gained (Na Free Gain) and total fluid gain in liters. 


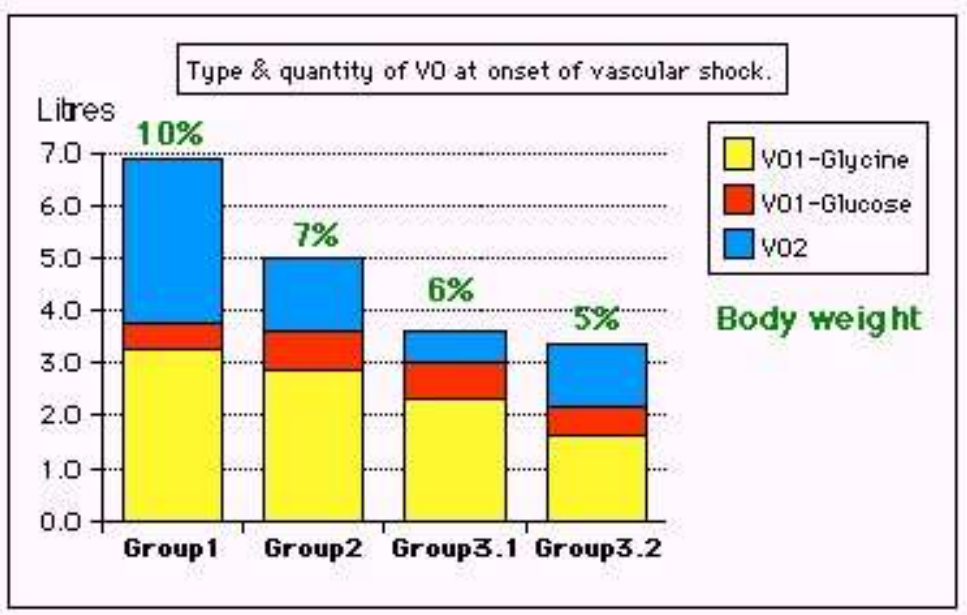

Figure 2. The volumetric overload (VO) quantity (in litres and as percent of body weight) and types of fluids. Group 1 was the 3 patients who died in the case series as they were misdiagnosed as one of the previously known shocks and treated with further volume expansion. Group 2 were 10 patients from the series who were correctly diagnosed as volumetric overload shock and treated with hypertonic sodium therapy (HST). Group 3 were 10 patients who were seen in the prospective study and subdivided into 2 groups; Group 3.1 of 5 patients treated with HST and Group 3.2 of 5 patients who were treated with guarded volume expansion using isotonic saline.

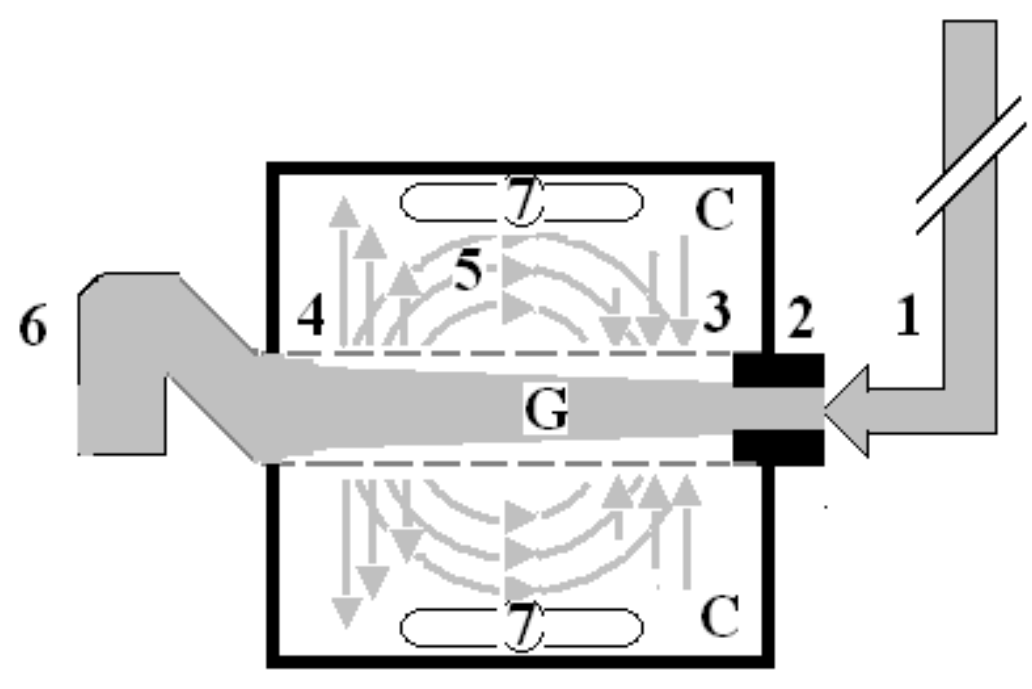

Figure 3. A diagrammatic representation of the hydrodynamic of $\mathrm{G}$ tube based on $\mathrm{G}$ tubes and chamber $\mathrm{C}$. This 37-years old diagrammatic representation of the hydrodynamic of $\mathrm{G}$ tube in chamber $\mathrm{C}$ is based on several photographs. The $\mathrm{G}$ tube is the plastic tube with narrow inlet and pores in its wall built on a scale to capillary ultra-structure of precapillary sphincter and wide inter cellular cleft pores, and the chamber $\mathrm{C}$ around it is another bigger plastic tube to form the G-C apparatus. The chamber $\mathrm{C}$ represents the ISF space. The diagram represents a capillary-ISF unit that should replace Starling's law in every future physiology, medical and surgical textbooks and added to chapters on hydrodynamics in physics textbooks. Medical students of today and tomorrow should be taught about it. The numbers should read as follows:

1. The inflow pressure pushes fluid through the orifice

2. Creating fluid jet in the lumen of the $G$ tube**.

3. The fluid jet creates negative side pressure gradient causing suction maximal over the

1. Proximal part of the $G$ tube near the inlet that sucks fluid into lumen.

4. The side pressure gradient turns positive pushing fluid out of lumen over the distal

2. Part maximally near the outlet.

5. Thus, the fluid around $\mathrm{G}$ tube inside $\mathrm{C}$ moves in magnetic fieldlike circulation (5)

3. Taking an opposite direction to lumen flow of $\mathrm{G}$ tube.
6. The inflow pressure 1 and orifice 2 induce the negative side pressure creating the dynamic G-C circulation phenomenon that is rapid, autonomous, and efficient in moving fluid and particles out from the $\mathrm{G}$ tube lumen at 4 , irrigating $\mathrm{C}$ at 5 , then sucking it back again at 3 ,

7. Maintaining net negative energy pressure inside chamber $\mathrm{C}$.

**Note the shape of the fluid jet inside the G tube (Cone shaped), having a diameter of the inlet on right hand side and the diameter of the exit at left hand side (G tube diameter). I lost the photo on which the fluid jet was drawn, using tea leaves of fine and coarse sizes that runs in the center of $\mathrm{G}$ tube leaving the outer zone near the wall of $\mathrm{G}$ tube clear. This may 
explain the finding in real capillary of the protein-free (and erythrocytefree) sub-endothelial zone in the Glycocalyx paradigm. It was also noted that fine tea leaves exit the distal pores in small amount maintaining a higher concentration in the circulatory system than that in the $\mathrm{C}$ chamberakin to plasma proteins.

After that Ghanem has continued alone to identify VOS 2 induced by sodium-based fluids as the patho-aetiology of ARDS and validate HST in its successful lifesaving therapy [5]. Ghanem and Ward introduced the concept of volumetric overload in the patho-aetiology of TURP syndrome reported in a prospective randomized cohort study in 1990 [10], reported in the British Journal of Urology- now International. Ghanem also investigated the underlying faulty physiological law of Starling for the capillary interstitial fluid transfer proving it wrong on both forces that should be replaced by the hydrodynamic of the porous orifice $(\mathrm{G})$ tube (Figure 3). Every word, sentence, statement, references and figures and tables mentioned here are reproduced from reference $[6]$.

Drug companies have been working hard with enormous amount of money to develop a safe and effective vaccine for Covid-19- this is for future prevention that is uncertain to predict after how long time it can protect people. I have been working equally hard from my home in Egypt in complete isolation and confinement quarantine since Covid-19 started its war against humanity a year or so ago. I shall continue to do so at home in the UK until the war is over. I work 20 hours per day and sleep only 4 interrupted noncontinuous hours per 24-hours a day. During my long sleepless nights and days, I do not feel a moment of boredom or dullness at all and there is nothing that I need that does not come to me with the help of family members, my wife Nannah Abdullatif and daughter Sarah, and a dear friend of mine Mr. Ahmed Awad. I do not miss seeing the streets or shops but miss seeing my friends once weekly every Friday at a local social club. This quarantine period of isolation and confinement at home of approximately one year was spent most productively and usefully in authoring approximately $>75$ articles and 8 books.

In the passenger allocation form that all passengers entering the UK must fill by law 48 hours before landing, it asked whether I wish to shorten the 10-days period of quarantine at home. There was not a question whether I wish to voluntarily extend it for as long as the Covid-19 pandemic lasts. I would have answered yes because I am on a voluntary mission to end this pandemic war lockdown against Covid-19 triumphantly within $<2$ months- if other scholars researchers co-operated with me and conducted the required suggested study $[7,8]$ that I cannot do myself being retired without access to work and research facilities. I anticipated the cooperation of journals in reporting this article immediately.

I work without any external financial help at all to help in the research that validate both the aetiology of ARDS and the effective therapy of concentrated salt solution of $5 \% \mathrm{NaCl}$ and/or $8.4 \% \mathrm{NaCo}_{3}$ in treating $\mathrm{VOS}$ that causes ARDS. I have fallen in debt to my bank for the first ever time in my life to finance my research and pay APC in OAJ because I believe it worthwhile investment and a good value for my money.

This HST is a definitive lifesaving therapy for patients who have developed ARDS and usually die in hundreds of thousands all over the world, so it should work on that caused by Covid-19 and sepsis [6] as well as the acutely ill patients and patients undergoing prolonged major surgery who suffer from ARDS and present during their hospital stay.

I know that the challenge and the stake or risk is extremely high, and I am taking a huge gamble, but it is only my reputation being at a vulnerable stake here, and it is only my money that is being invested. HST will not cost anybody but me any money and will not put your patients at any risk and will not cause any side effects- it is $100 \%$ guaranteed. To make it easy for every doctor managing ARDS cases of Covid-19 particularly Intensivists and anaesthetists running ICU I shall go absolutely daring to say try a pilot study on 5 patients and report your conclusion fast. It is perfectly acceptable to me for validating my theory so it should be accepted by the journal of your choice as valid evidence in support of the theory and on my responsibility.

During a war emergency law apply and overrules the usual rules and regulations, and even may put some laws on hold. I shall accept your verdict and you will be my witness and alibi. During a war rules and regulations may be over-ruled and even laws may be made temporarily redundant. We are at war against Covid-19 and its ARDS. This is an instant positive success for you that would delight me and the rest of the World. This is my fascinating true story of 40 -years ongoing research that has many starts: the one of relevance hear is the writing of my first essay to the Lancet after obtaining my MD Thesis in Nov. 1988. This amazing success story has not ended yet and I may write it up some day either in Arabic or English if I find the time or leave it to a professional story writer that may interest film makers later. Of all the movies I have seen in cinemas and on TV Amadeus remains my best favorite film so far.

The rewards of my endeavor might be equal or greater than the gamble on the theory of using HST for treating ARDS of Covin-19. It is a calculated risk. I trust my observations, scientific acuity, and the results and conclusions of my 40-years professional research that would not let me down now. Please trust me and have faith in me as I can do what I say I can. Egypt no longer needs my help as there is no lockdown there now except some limit on the opening times of shops and cafes and people are enjoying perfectly normal life despite high rate of Covid-19 mortality. Furthermore, to Egypt and perhaps the whole Arabic World I am like petrol available under their feet, but it only has value when discovered by the West professional expertise. The UK and USA do need my help and would appreciate it to end their current state of lockdown and to save the lives of their patients. This explains why I am here in the UK now. The whole world shall appreciate my help to reduce or prevent mortality of ARDS due to Covid-19 as well as sepsis and other predisposing factors. This is how I put my money where my mouth is. The race is on. Prove me wrong if you dare! Just kidding I should say please if you care.

\section{Addendum}

The author is available to all interested researchers 24/7 (++44) (0) 7306321589) to answer any questions or provide any clarification on the suggested trial and HST. If you do not get an answer this is because I am on one of my interrupted irregular sleep break of 1-h every 3-5 hours. Please call again after one hour or send me an email on: anmghanem1@gmail.com Communication may be in English or Arabic, if you cannot speak and write in these languages please use your own that will be automatically translated for me by Google.

\section{Conflict of interest: None}

Funds received: None

\section{References}

1. Philips Nicki. (2021) The coronavirus s here to stay-here's what that means. Nature 590, 382-384.

2. Ghanem AN. (2021) Volumetric overload shocks or volume kinetic shocks in clinical practice. Resolving the puzzles of the transurethral resection of the prostate (TURP) syndrome, acute dilution hyponatraemia (HN) and the acute respiratory distress syndrome (ARDS)". Book. Scholars Press USA .2018 1st edition and 20212 nd edition.

3. Ghanem AN.(2021) Scientific Discoveries of the 21st century Book. Scholars Press 1st edition.

4. Ghanem AN. (2020) The scientific basis of fluid therapy in shock: Based on new scientific discoveries in physics, physiology, and medicine. Book. Eliva Press. 
5. Ghanem AN. (2021) Acute Respiratory Distress Syndrome (ARDS): Is it relevant to Covid-19 pandemic ARDS? The puzzle is resolved being recognized as an iatrogenic complication of fluid therapy that induce volumetric overload shocks (VOS) and cause ARDS. Eliva Press (In the press)

6. Ghanem AN. (2021) New scientific basis of fluid therapy in shock management: The complications. The complete evidence based on new scientific discoveries in physics, physiology, and medicine. Austin Macauley Publishers Ltd @, London, New York, Cambridge, Sharjah. (In the press). Comes in 36 Chapters and 516 pages.

7. Ghanem AN. (2021) stupidity and utter stupidity: a problem without solution and malady without cure!? Perspective. Ec Emergency Medicine and Critical Care 5.3.

8. Ghanem AN. (2021) Impact of Covid-19 on Surgery and Anaesthesia: Fighting another Unique War on ARDS Relevant to Covid-19 Pandemic. EC Emergency Medicine and Critical Care 5.2 .
9. Ghanem AN. (2021) Cardiovascular and hematological manifestations of the acute respiratory distress syndrome (ards) caused by the newly discovered volumetric overload shocks (vos). Is it relevant to covid-19 pandemic ards? Ec Emergency Medicine and Critical Care 5.3.

10. Ghanem AN, Ward JP (1990). Osmotic and metabolic sequelae of volumetric overload in relation to the TURP syndrome. $\mathrm{Br} . J$. Urol. 66: 71-78

11. Danowski TS, Winkler AW, Elkington JR. (1946) The treatment of shock due to salt depression comparison of isotonic, of hypertonic saline and of isotonic glucose solutions. Journal of Clinical Investigation 25.1. 130-138.

12. Harrison, R.H., Boren, J.S. and Robinson, J.R. (1956) Dilutional hyponatraemic shock: another concept of the transurethral prostatic reaction. J. Urology. 75.1. 95-110.

13. Ghanem AN, Wojtulewski JA, Penny MD. (1987) Dangers in treating hyponatraemia. Br Med J (Clin Res Ed) 294: 837.

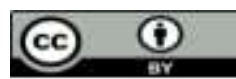

This work is licensed under Creative Commons Attribution 4.0 License

\section{To Submit Your Article Click Here: Submit Manuscript}

DOI: $10.31579 / 2690-8794 / 069$
Ready to submit your research? Choose Auctores and benefit from:

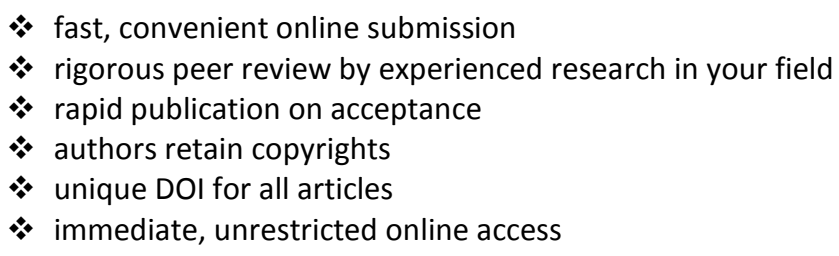

At Auctores, research is always in progress.

Learn more www.auctoresonline.org/journals/clinical-medical-reviewsand-reports 